\title{
Factors influencing the deterioration from cognitive decline of normal aging to dementia among nursing home residents
}

\author{
Audai A. Hayajneh ${ }^{1 *} \mathbb{D}$, Mohammad Rababa $^{1}$, Alia A. Alghwiri ${ }^{2}$ and Dina Masha'al
}

\begin{abstract}
Background: A dearth of differential research exists regarding the determinants of mild cognitive impairment (MCl) and moderate cognitive impairment or dementia among nursing home residents. This study aimed to identify and examine the association between medical factors (number of comorbidities, hospitalization, disability, depression, frailty and quality of life) and moderate cognitive impairment or dementia in nursing homes residents.

Methods: A cross-sectional design was used in this study. Convenience sampling of 182 participants was conducted in nursing homes located in the central part of Jordan. Montreal cognitive assessment (MoCA) was used to screen both $\mathrm{MCl}$ and moderate cognitive impairment or dementia. Bivariate analysis, including t-test and ANOVA test, and logistic and linear regression models were used to examine and identify the medical factors associated with moderate cognitive impairment or dementia compared to mild cognitive impairment.
\end{abstract}

Results: Most nursing home residents had $\mathrm{MCl}(87.4 \%)$ compared to a few with moderate cognitive impairment or dementia. Age $(t=-2.773)$, number of comorbidities $(t=-4.045)$, depression $(t=-4.809)$, frailty $(t=-4.038)$, and quality of life physical $(t=3.282)$ and mental component summaries $(t=2.469)$ were significantly different between the stages of cognitive impairment. Marital status ( $t=-4.050, p<0.001)$, higher-income $(t=3.755, p<0.001)$, recent hospitalization ( $t=2.622, p=0.01)$, depression ( $t=-2.737, p=0.007)$, and frailty $(t=2.852, p=0.005)$ were significantly associated with mental ability scores among nursing home residents.

Conclusion: The coexistence of comorbidities and depression among nursing home residents with $\mathrm{MCl}$ necessitates prompt management by healthcare providers to combat depressive symptoms in order to delay the dementia trajectory among at-risk residents.

Trail registration: ClinicalTrials.gov NCT04589637, October 15,2020, Retrospectively registered.

Keywords: Cognitive decline, Normal aging, Dementia, Nursing homes residents, Impairment

\footnotetext{
* Correspondence: aahayajneh@just.edu.jo

${ }^{1}$ Adult health-nursing department, Faculty of Nursing, Jordan University of

Science and Technology, P.O. Box: 3030, Irbid 22110, Jordan

Full list of author information is available at the end of the article
}

(c) The Author(s). 2020 Open Access This article is licensed under a Creative Commons Attribution 4.0 International License, which permits use, sharing, adaptation, distribution and reproduction in any medium or format, as long as you give appropriate credit to the original author(s) and the source, provide a link to the Creative Commons licence, and indicate if changes were made. The images or other third party material in this article are included in the article's Creative Commons licence, unless indicated otherwise in a credit line to the material. If material is not included in the article's Creative Commons licence and your intended use is not permitted by statutory regulation or exceeds the permitted use, you will need to obtain permission directly from the copyright holder. To view a copy of this licence, visit http://creativecommons.org/licenses/by/4.0/. The Creative Commons Public Domain Dedication waiver (http://creativecommons.org/publicdomain/zero/1.0/) applies to the data made available in this article, unless otherwise stated in a credit line to the data. 


\section{Background}

The decline in normal cognitive ability may be acute, chronic, or a sign of confusion related to delirium, dementia, major depression, or psychosis [1]. Mild cognitive impairment $(\mathrm{MCI})$ is considered a transitional phase between normal cognition and dementia, in which customized interventions can be directed at this phase, aiming to stop its deterioration to dementia among older adults [2]. MCI is considered the "symptomatic predementia stage" on the gamut of cognitive decline [3].

Nursing homes are one of the places where older people or geriatric patients are institutionalized. Some institutionalized residents suffer from cognitive decline or cognitive impairment as well as dementia [4]. In addition to cognitive impairment [5], nursing home residents are at higher risk for frailty and dependency with aging [6]. Earlier studies showed that the prevalence rate of cognitive impairment in similar contexts ranged from 67 to $73 \%[5,7,8]$.

Cognitive impairment in nursing home residents should be focused upon because of higher severity compared to that of community-dwelling older adults [9]. Most of the nursing home residents in Jordan are not admitted based on specific medical admission criteria [10], which indicates that information is still limited regarding their healthcare needs as well as factors influencing their cognitive ability. Numerous factors were found to be associated with cognitive impairment or the risk of incidental dementia, such as frailty [11], depression [12], and health-related quality of life (HRQoL) [13, 14]. However, the factors of transition from mild cognitive impairment to moderate cognitive impairment stage or dementia among older adults have not been extensively understood in the literature.

Complete understanding of the stages of mild and moderate cognitive impairment, as concepts having their own attributes and features, significantly contributes to preventing and determining the trajectory of dementia as well as preparing management approaches for the admission of older individuals into nursing homes [15]. In light of this context, the aims of this study were to: 1) identify and examine the association between some selected medical factors (number of comorbidities, hospitalization, disability, depression, frailty and quality of life) and cognitive impairment or dementia in nursing homes residents, and 2) examine the association between the life course determinants (age, sex, education, income, and marital status) and moderate cognitive impairment or dementia.

\section{Methods}

\section{Study design and setting}

A cross-sectional design was used in the current study. Convenience sampling of 182 participants was used to obtain moderate size correlation $(\mathrm{r}=0.35)$, given a power of 0.80 , two-sided Type I error rate of $p=0.0167$, based on nQuery calculation [16]. The participants were recruited from 5 holistic nursing homes, including private and public nursing homes, located in the center of Jordan. Inclusion criteria were as follows: Jordanian participants, aged 60 years and older, and living in nursing homes. Exclusion criteria were neurological disorders, such as stroke or brain injury.

\section{Instruments}

A demographic and health survey was developed by the principal investigator, including age, sex, education level, household income, marital status, impaired activities of daily living, the number of comorbidities, and the number of hospitalizations during the year before (See Additional file 1). The Arabic version-Montreal Cognitive Assessment (MoCA) tool was used to detect both mild and moderate cognitive impairment based on its total score [17] (See Additional file 1). It has 10 items about different cognitive domains (executive functions, memory, language, attention and concentration, conceptual thinking, calculations, visuoconstructional skills, and orientation). The total score of the test is a 30-point score and it takes 10 min to administer. A score of 26 or above indicates no cognitive impairment. The sensitivity of the cutoff score to detect MCI is $90 \%$ and to detect mild Alzheimer's disease is $100 \%$, and its specificity has been reported to be excellent (87\%) [18]. A total score of 18 to 25 was considered mild cognitive impairment, and a score of 10 to 17 was considered moderate cognitive impairment [17] or dementia. The MoCA tool was developed by Dr. Nasreddine and colleagues (2005), who has extensively used this tool in detecting cognitive impairment in nursing home residents. Using the MoCA has been welldocumented in the literature to determine mild and moderate cognitive impairment [17]. In conclusion, the MoCA is the most precise cognitive ability measure that differentiate between the stages of cognitive impairment and had excellent sensitivity and specificity values to detect $\mathrm{MCI}$ and mild Alzheimer's disease [18] compared to other cognitive ability measures.

The Arabic version-geriatric depression scale (GDS) was used to detect depression and it has 15 items. The total score was 15 and its scores were distributed as follows: 0-4 normal, 5-8 mild depression, 9-11 moderate depression, and 12-15 severe depression [19]. Greenberg's study revealed that the GDS-15 had high sensitivity and specificity of 92 and 89\%, respectively [19] (See Additional file 1).

The Arabic version-HRQoL (Short Form (SF-36)) was used in the current study. The SF-36 health survey entails 2 main domains (physical and mental). The SF-36 health survey has 36 questions, including 8 categories: physical functioning (PF), general health $(\mathrm{GH})$, vitality $(\mathrm{V})$, social functioning (SF), role-physical (RP), bodily pain (BP), mental health $(\mathrm{MH})$, and role-emotional (RE). Each category has a 0-100 scale calculated using a 
special software. Lower score indicates more disability, and a higher score shows less disability/higher HRQoL in its category [20]. The scores of the Arabic-SF-36v2 ${ }^{\circ}$ were calculated using Qualtrics Software (Medical Outcomes Trust) (See Additional file 1).

The Arabic version-Tilburg frailty indicator (TFI) was used in the current study to assess frailty among Jordanian older adults. The original TFI created by Gobbens and colleagues [21] has 15 items, entailing 3 domains: physical, psychological, and social domains. The reliability $(\mathrm{KR} 20=0.77)$ and convergent and divergent validity of the Arabic version-TFI have been established in Jordanian population [22]. The TFI is the only frailty instrument that has been translated and validated to use in Jordanian older adult population [22]. It has only fifteen questions [21], which is easy to administer in older adult population (See Additional file 1).

\section{Data collection}

After institutional review board (IRB) approval (\#20180229) from both the Jordan University of Science and Technology and targeted nursing homes, participants of the study were recruited through nursing home visits and asked to participate in the study. An overseeing mental health expert have ruled that all participants have been deemed capable of ethically and medically consenting for their participation in the study. Consent forms were delivered to or read aloud to the older adults prior to collecting data from them. To avoid drift resulting from different data collectors, a training session on how to gain information using the instruments used in the current study was conducted for data collectors.

\section{Statistical analysis}

Bivariate analysis, including t-test and ANOVA test, was used to examine the correlations between health variables and mental ability. Thereafter, multivariate analysis, including logistic and linear regression models was conducted, for the correlations between health variables and both mild and moderate cognitive impairment. The statistical analysis was performed using the Statistical Package for Social Sciences (SPSS) version 25 (SPSS, Inc., Chicago, Ill).

\section{Results}

Altogether, 182 nursing home residents participated in the current study. Most of them had MCI (87.4\%) compared to a few with moderate cognitive impairment or dementia. Their mean age was 64.42 years $(S D=10.32)$ and most of them were male $(91.3 \%)$. Only 24 participants were not married (13\%). The largest percentage of the participants included residents with secondary school education (18.7\%). Most of the participants who answered the question about monthly income had less than 450 JOD (USD 630). The number of governmental nursing homes residents was 103 (56.3\%). Only 3.3\% of the participants had disability and $73.8 \%$ had frailty.

The mean depression total score was 6.148 (SD = 3.644). One hundred and sixty participants had mild cognitive impairment $(87.4 \%)$ and the rest had moderate cognitive impairment (12.6\%). Most of the 8 components of the SF36 health survey were approximately 50\% on the scale, which represents a range from 0 (worst quality of life) to $100 \%$ (highest quality of life). Two main domains of HRQoL (physical and mental) among participants were 47 and $46 \%$, respectively (Table 1 ).

Table 2 displays the associations between the demographic and health characteristics of nursing home residents and the stages of mild and moderate cognitive impairment. Residents were significantly older in the moderate $($ mean $=68.8, \mathrm{SD}=13.03)$ than in the mild (mean $=63.8, \quad \mathrm{SD}=9.79$ ) cognitive impairment group $(\mathrm{t}=-2.773, p=0.031)$. The number of comorbidities was higher in the moderate group (mean $=3.18, \mathrm{SD}=$ 2.22) than in the mild cognitive impairment group $(\mathrm{t}=-$ $4.045, p<0.001)$. Nursing home residents who were hospitalized during the year before were likely to have moderate cognitive impairment $(p=0.016)$ than those who were not hospitalized (23.07 to $7.75 \%$ ).

Depression in nursing home residents was significantly higher in the moderate (mean $=9.45, \mathrm{SD}=3.95$ ) than in the mild (mean $=5.69, \mathrm{SD}=3.36)$ cognitive impairment group $(\mathrm{t}=-4.809, p<0.001)$. Pertaining to frailty, nursing home residents had significantly more frailty in the moderate $($ mean $=10.86, \mathrm{SD}=2.95)$ than in the mild (mean $=7.46, \mathrm{SD}=3.79$ ) cognitive impairment group $(\mathrm{t}=-4.038, \mathrm{p}<0.001)$. The two main branches of HRQoL (physical and mental) as well as their components, were significantly better in the mild compared to the moderate cognitive impairment group $(p<0.05)$, except for the role-physical component, which was not significant $(p=0.09)$ (Table 2$)$.

A logistic regression model using a stepwise regression method was used to identify and explore coexisted factors of moderate cognitive impairment among nursing home residents. Only significant variables after bivariate analysis were chosen to build the primary model for the coexisting factors of the moderate cognitive impairment stage. These variables were age, the number of comorbidities, hospitalization, depression, frailty, and physical and mental component summaries for quality of life (Table 3). The indices of goodness of fit for the yielded logistic regression model are shown in Table 4, which were considered acceptable.

Model 4 (Table 3) yielded two significant medical factors of moderate cognitive impairment, depression $(p<0.001)$ and the number of comorbidities $(p=0.021)$. The indices of model 4 showed adequate fit based on 
Table 1 Social-Demographic and health characteristics of nursing homes residents $(N=182)$

\begin{tabular}{lll}
\hline & N (\%) & Mean (SD) \\
\hline Age & & $64.42(10.32)$ \\
Sex & & \\
$\quad$ Male & $167(91.3)$ & \\
$\quad$ Female & $15(8.7)$ \\
Marital Status & \\
$\quad$ Married & $158(86.8)$ \\
$\quad$ Non married & $24(13.2)$ \\
Education & \\
$\quad$ Illiterate & $22(12.1)$ \\
$\quad$ Non-Illiterate & $160(87.9)$ \\
Income (Jordanian Dinars) & \\
$\quad<450$ & $172(94.5)$ \\
$\quad>450$ & $10(5.5)$
\end{tabular}

Type of nursing homes

$\begin{array}{ll}\text { Governmental } & 103(56.6) \\ \text { Private } & 79(43.4)\end{array}$

The number of comorbidities

\section{Disability}

$$
\text { Yes }
$$

No

Hospitalization
Yes
No
Depression (GDS)
Frailty (TFI)
Frail

Non frail

Cognitive Impairment (MoCA) Mild

Moderate (dementia)

Quality of Life (SF36)

Physical Functioning (PF)

Role Physical (RP)

Bodily Pain (BP)

General Health $(\mathrm{GH})$

Vitality (VT)

Social Functioning (SF)

Role Emotional (RE)

Mental Health (MH)

Physical Components Summary

Mental Components Summary
$37.77(8.82)$
$47.72(8.23)$
$52.77(8.13)$
$49.31(9.25)$
$46.95(8.84)$
$48.08(7.95)$
$45.50(9.53)$
$42.58(7.10)$
$\mathbf{4 7 . 0 0}(\mathbf{7 . 7 3})$
$\mathbf{4 6 . 0 3}(\mathbf{7 . 0 9})$ the non-significant $p$ value of the chi-square test $(p=$ 0.141 ) and low values of both AIC and BIC. AIC and $\mathrm{BIC}$ values represented the lowest error measurements values of 117.183 and 129.999, respectively. Based on model 4, for any additional score increases on the depression scale, the odds of moderate cognitive impairment increased by $30.4 \%$. Moreover, for any additional comorbidity among nursing home residents, the odds of moderate cognitive impairment increased by $54 \%$. However, age was not significant in Model 4 (Table 3).

Linear regression models of life course determinants and medical factors have been shown in Tables 5 and 6, respectively. Among nursing home residents, marital status $(\mathrm{t}=-4.050, p<0.001)$, higher-income $(\mathrm{t}=3.755, p<0.001)$, recent hospitalization $(\mathrm{t}=2.622, p=0.01)$, depression $(\mathrm{t}=-$ 2.737, $p=0.007)$, and frailty $(\mathrm{t}=2.852, p=0.005)$ were significantly associated with low mental ability.

\section{Discussion}

The main aim of this study was to identify the factors that lead to the conversion from MCI to moderate cognitive impairment or dementia in nursing home residents. The reason of very young nursing home residents in our study is that older adulthood in Jordan is most commonly defined at age of 55 years [23, 24]. Pertaining to inequal sexes in our sample, cultural considerations and social stigma play a genuine role in determining where older adults are living, and who care for them [10, 25, 26] or discouraging Arab families from admitting their older relatives to nursing homes [27]. This could explain the small percentage of female nursing home participants in our study as it might be unacceptable for Jordanian female older adults to be admitted to nursing homes. Based on the logistic regression model, depression and the number of comorbidities were found to be significantly associated with moderate cognitive impairment or dementia in this population. Depression contributes significantly to dementia through its effects on the dementia trajectory [28]. This contribution has been reported in a previous recent study [28]. This is in line with the findings of Makizako and colleagues [29]. Their study reported that the coexistence of depression and MCI significantly predisposes older adults to dementia.

Similar to our results in the current study, depression was found to be common among patients with MCI and cognitive deficits [30], placing those patients at higher risk for dementia in their later years. This combination of depression and MCI complicates the health condition of these patients at later stages of life, particularly affecting their treatment for combating cognitive decline, such as donepezil for Alzheimer's disease as reported by Devanand and colleagues [31].

The negative effect on the treatment approaches managing cognitive decline is not the only health challenge

Note: GDS: Geriatric depression scale, TFI: Tilburg frailty indicator, MoCA Montreal cognitive assessment 
Table 2 Bivariate analysis for the associations between demographic and health characteristics of nursing homes residents and the stages of mild and moderate cognitive impairment $(N=182)$

\begin{tabular}{|c|c|c|c|c|c|}
\hline \multirow[b]{2}{*}{ Age } & \multirow{2}{*}{$\begin{array}{l}\begin{array}{l}\text { Statistic } \\
\text { tests }\end{array} \\
\mathrm{t}=-2.773\end{array}$} & \multicolumn{2}{|c|}{$\begin{array}{l}\text { Mean (SD) or } n(\%) \\
\text { Cognitive Impairment } \\
\text { Mild (160) vs. Moderate (22) }\end{array}$} & \multirow[t]{2}{*}{ df } & \multirow{2}{*}{$\begin{array}{l}p \text {-value } \\
0.031\end{array}$} \\
\hline & & $63.8(9.79)$ & $68.8(13.03)$ & & \\
\hline \multicolumn{6}{|l|}{ Sex } \\
\hline Female & $X^{2}=0.024$ & $13(86.67)$ & $2(13.33)$ & 1 & 0.877 \\
\hline Male & & $147(88.02)$ & $20(11.98)$ & & \\
\hline \multicolumn{6}{|l|}{ Marital Status } \\
\hline Married & $X^{2}=36.7$ & $22(91.68)$ & $2(8.32)$ & 1 & 0.545 \\
\hline Non-married & & $138(87.34)$ & $20(12.66)$ & & \\
\hline \multicolumn{6}{|l|}{ Education } \\
\hline $\begin{array}{l}\text { Illiterate } \\
\text { Non illiterate }\end{array}$ & Fisher's $=0.875$ & $\begin{array}{l}18(81.82) \\
142(88.75)\end{array}$ & $\begin{array}{l}4(81.18) \\
18(11.25)\end{array}$ & & 0.303 \\
\hline \multicolumn{6}{|l|}{ Income (Jordanian dinars) } \\
\hline$<450 J O D$ & Fisher's $=0.04$ & $151(87.80)$ & $21(12.20)$ & & 0.835 \\
\hline$>450 \mathrm{JOD}$ & & $9(90)$ & $1(10)$ & & \\
\hline \multicolumn{6}{|l|}{ Type of nursing homes } \\
\hline Governmental & $X^{2}=0.505$ & $71(89.87)$ & $8(10.13)$ & & 0.47 \\
\hline Private & & $89(86.40)$ & $14(13.60)$ & & \\
\hline The number of comorbidities & $t=-4.045$ & $1.75(1.414)$ & $3.18(2.22)$ & & $<0.001$ \\
\hline \multicolumn{6}{|l|}{ Hospitalization } \\
\hline Hospitalized during last year & $X^{2}=8.329$ & $40(76.92)$ & $12(23.08)$ & 2 & 0.016 \\
\hline Non-hospitalized during last year & & $119(92.25)$ & $10(7.75)$ & & \\
\hline \multicolumn{6}{|l|}{ Disability } \\
\hline $\begin{array}{l}\text { With disability } \\
\text { Without disability }\end{array}$ & $x^{2}=0.303$ & $\begin{array}{l}4(80) \\
156(88)\end{array}$ & $\begin{array}{l}1(20) \\
21(12)\end{array}$ & 1 & 0.582 \\
\hline Depression & $t=-4.809$ & $5.69(3.36)$ & $9.45(3.95)$ & 180 & $<0.001$ \\
\hline Frailty & $t=-4.038$ & $7.46(3.79)$ & $10.86(2.95)$ & & $<0.001$ \\
\hline \multicolumn{6}{|l|}{ Quality of life } \\
\hline Physical Functioning & $t=3.605$ & $38.62(8.51)$ & $31.61(8.79)$ & 180 & $<0.001$ \\
\hline Role Physical & $t=1.659$ & $48.10(7.89)$ & $45.01(10.2)$ & 180 & 0.09 \\
\hline Bodily Pain & $t=2.645$ & $53.35(7.43)$ & $48.54(11.3)$ & 180 & 0.009 \\
\hline General Health & $t=3.451$ & $50.17(8.64)$ & $43.11(11.28)$ & 180 & $<0.001$ \\
\hline Vitality & $t=2.656$ & $47.59(8.54)$ & $42.33(9.82)$ & 180 & 0.009 \\
\hline Social Functioning & $t=3.291$ & $48.78(7.15)$ & $42.98(11.3)$ & 180 & 0.001 \\
\hline Role Emotional & $t=2.062$ & $46.04(9.01)$ & $41.6(12.28)$ & 180 & 0.041 \\
\hline Mental Health & $t=2.318$ & $43.03(6.98)$ & $39.33(7.25)$ & 180 & 0.022 \\
\hline Physical Components Summary & $\mathrm{t}=3.282$ & $47.68(7.46)$ & $42.07(8.03)$ & 180 & 0.001 \\
\hline Mental Components Summary & $t=2.469$ & $46.50(6.52)$ & $42.57(9.82)$ & 180 & 0.041 \\
\hline
\end{tabular}

among these patients. The presence of comorbidities, such as diabetes mellitus, in addition to depression and MCI among older adults, necessitates early assessment and proper management to achieve better quality of life [32]. In our study, HRQoL was significantly correlated with the stages of cognitive impairment. This confirms the findings of the study by Liu and colleagues [33], in which
MCI alone or with other comorbidities was found to be significantly and negatively associated with HRQoL.

In the current study, the number of comorbidities was significantly associated with moderate cognitive impairment or dementia, which contributes to progression of MCI to dementia among nursing home residents. Numerous comorbidities in the literature have been found to be 
Table 3 Logistic regression model of predictors of moderate vs. mild cognitive impairment

\begin{tabular}{|c|c|c|c|c|c|c|c|}
\hline \multirow{2}{*}{$\begin{array}{l}\text { Model } \\
1\end{array}$} & \multirow{2}{*}{$\begin{array}{l}\text { Parameter } \\
\text { (Intercept) }\end{array}$} & \multirow{2}{*}{$\begin{array}{l}\text { Estimate } \\
-1.984\end{array}$} & \multirow{2}{*}{$\begin{array}{l}\text { Standard Error } \\
0.227\end{array}$} & \multirow{2}{*}{$\begin{array}{l}\text { Adjusted } \\
\text { Odds Ratio }\end{array}$} & \multirow{2}{*}{$\begin{array}{l}\mathbf{p} \\
<.001\end{array}$} & \multicolumn{2}{|c|}{$\begin{array}{l}\text { Confidence Interval } \\
\text { Lower Upper } \\
\text { bound bound }\end{array}$} \\
\hline & & & & & & -2.430 & -1.538 \\
\hline \multirow[t]{2}{*}{2} & (Intercept) & -4.043 & 0.619 & 0.018 & $<.001$ & -5.257 & -2.829 \\
\hline & Depression & 0.275 & 0.066 & 1.317 & $<.001$ & 0.146 & 0.404 \\
\hline \multirow[t]{3}{*}{3} & (Intercept) & -4.319 & 0.667 & 0.013 & $<.001$ & -5.626 & -3.011 \\
\hline & Depression & 0.223 & 0.073 & 1.250 & 0.002 & 0.081 & 0.365 \\
\hline & The number of comorbidities & 0.271 & 0.149 & 1.312 & 0.068 & -0.020 & 0.563 \\
\hline \multirow[t]{4}{*}{4} & (Intercept) & -1.554 & 1.955 & 0.211 & 0.427 & -5.387 & 2.278 \\
\hline & Depression & 0.265 & 0.080 & 1.304 & $<.001$ & 0.109 & 0.422 \\
\hline & The number of comorbidities & 0.432 & 0.187 & 1.540 & 0.021 & 0.065 & 0.798 \\
\hline & Age & -0.052 & 0.036 & 0.949 & 0.146 & -0.123 & 0.018 \\
\hline
\end{tabular}

Note: Stepwise regression method

associated with $\mathrm{MCI}$ and dementia, such as cerebrovascular disease, cirrhosis, asthma, and diabetes mellitus [34]. Dementia severity is also dependent on the severity of each comorbidity [35]. However, this is not in accordance with a previous report [36] that revealed that the prevalence of comorbidities, except anemia, was similar across different cognitive impairment stages. Further research is needed to explore the extent to which each comorbidity contributes to cognitive impairment among nursing home residents.

According to linear regression models in the current study, marital status was significantly associated with mental ability. This is in concordance with another study [37] that reported older individuals living alone are at higher risk for common mental disorders, and this justifies that single or unmarried residents might have low mental ability. Therefore, it places them at higher risk for moderate cognitive impairment or dementia. Nursing home residents with higher income were found to have higher mental ability scores in our study. A similar report [38] suggested that poverty increases the risk of mental ability decline, and consequently, mental illness. This indicates how socio-economic status might contribute to changing mental ability scores towards moderate cognitive impairment or dementia. Recent hospitalizations were found to be associated with low mental ability in the current study. It is difficult to determine the relationship between length of hospital stay and cognitive

Table 4 The indices of goodness of fit for the yielded logistic regression model

\begin{tabular}{llllll}
\hline Model & AIC & BIC & df & $\Delta \mathbf{X}^{\mathbf{2}}$ & $\mathbf{p}$ \\
\hline 1 & 136.197 & 139.401 & 181 & & \\
2 & 118.525 & 124.933 & 180 & 19.672 & $<.001$ \\
3 & 117.347 & 126.959 & 179 & 3.178 & 0.075 \\
4 & 117.183 & 129.999 & 178 & 2.165 & 0.141 \\
\hline
\end{tabular}

decline, especially among older people because of multiple risk factors affecting their mental status during hospitalization, such as drug effects, surgery, stress, and discharge from hospital [39]. In addition, other diseases, such as anemia may influence the cognitive function in older adults during hospitalization [40]. Lastly, frailty was also significantly associated with a low mental ability score in our study. This is in concordance with a report [41] stating that frailty predisposes older individuals aged 68 years and above to incidental dementia. This outcome could help in developing interventions tailored to nursing home residents with frailty prior to the development of dementia.

Although age was found to be significantly and negatively correlated with stages of cognitive impairment in the bivariate analysis of the current study, it was not a predictor of moderate cognitive impairment or dementia. This corroborates with established literature that normal aging changes are totally different from moderate cognitive impairment or dementia. MCI represents the intermediate phase between normal aging and dementia, where novel early interventions can be rendered by healthcare providers [42].

Table 5 Linear regression model one of covariate variables of mental ability

\begin{tabular}{lllll}
\hline Model & & Standardized & $\mathbf{t}$ & $\mathbf{p}$ \\
\hline 1 & (Intercept) & & 19.685 & $<.001$ \\
& Age & -0.198 & -2.236 & $\mathbf{0 . 0 2 7}$ \\
& Sex & -0.035 & -0.547 & 0.585 \\
& Marital status & -0.258 & -3.990 & $<.001$ \\
& Education & -0.018 & -0.275 & 0.783 \\
Income & 0.185 & 2.902 & $\mathbf{0 . 0 0 4}$ \\
& Type of nursing home & -0.088 & -1.334 & 0.184 \\
& The number of comorbidities & -0.274 & -3.137 & $\mathbf{0 . 0 0 2}$ \\
\hline
\end{tabular}

Model $1 \mathrm{R}^{2}=0.30$, Adjusted $\mathrm{R}^{2}=0.274, \mathrm{p}=<0.001$ 
Table 6 Linear regression model two of covariate variables and predictors of mental ability

\begin{tabular}{lllll}
\hline Model & & Standardized & $\mathbf{t}$ & $\mathbf{p}$ \\
\hline 2 & (Intercept) & & 7.113 & $<.001$ \\
& Age & 0.057 & 0.625 & 0.533 \\
& Sex & 0.012 & 0.204 & 0.838 \\
& Marital status & -0.237 & -4.050 & $<.001$ \\
& Education & -0.015 & -0.251 & 0.802 \\
& Income & 0.221 & 3.755 & $<.001$ \\
& Type of nursing home & -0.012 & -0.186 & 0.852 \\
& The number of comorbidities & -0.048 & -0.537 & 0.592 \\
& Hospitalization & 0.183 & 2.622 & $\mathbf{0 . 0 1 0}$ \\
& Disability & 0.019 & 0.313 & 0.755 \\
Depression & -0.240 & -2.737 & $\mathbf{0 . 0 0 7}$ \\
& Frailty & -2.852 & $\mathbf{0 . 0 0 5}$ \\
& PCS & -0.283 & -0.210 & 0.834 \\
& MCS & -0.016 & &
\end{tabular}

The ability to differentiate between normal aging and neurodegenerative etiology of the brain can contribute significantly to implementing the required management approach in a timely manner and delay additional cognitive decline [43] or developing dementia. Recognizing dementia-specific factors assists healthcare providers, including nurses, in setting up highly flexible and sensitive interventions, treatments, and protocols to meet patients' needs in nursing homes [44-46]. Further research should be conducted to address the extent to which we can consider cognitive changes that accompany normal aging and to what extent these changes are related to pathological conditions. Our study is not without limitations that are inherent in the cross-sectional design. However, the findings of this study shed light on the importance of comprehensive examination of nursing home residents, including detecting depression symptoms as well as documenting all existing comorbidities to design a specific plan of treatment that halts the deterioration of their cognitive abilities.

\section{Conclusion}

Being single, low income, recent hospitalization, depression, and frailty were significantly correlated with low mental ability, moderate cognitive impairment, or dementia among nursing home residents, leading to the progression of cognitive impairment. The age of nursing home residents was not a significant associated with moderate cognitive impairment or dementia. The coexistence of such medical factors among nursing home residents with $\mathrm{MCI}$ necessitates prompt management by healthcare providers in order to delay the dementia trajectory among those at-risk.

\section{Supplementary Information}

The online version contains supplementary material available at https://doi. org/10.1186/s12877-020-01875-3.

\section{Additional file 1.}

\section{Abbreviations}

MCl: Mild Cognitive Impairment; MoCA: Montreal Cognitive Assessment; GDS: Geriatric Depression Scale

\section{Acknowledgments}

The authors would like to thank Jordan University of Science and

Technology for funding this study.

Authors' contributions

All authors have read and approved the manuscript, We hereby confirm that all listed authors meet the authorship criteria and that all authors are in agreement with the content of the manuscript. Study conception \& design: $\mathrm{AH}$; data collection and analysis: $\mathrm{AH}, \mathrm{MR}, \mathrm{DM}$; data interpretation: $\mathrm{AH}, \mathrm{MR}$, $A A, D M ;$ and manuscript preparation: $A H, A A$; final approval of the manuscript version to be published: $\mathrm{AH}$.

\section{Funding}

This work was funded by the Jordan University of Science and Technology. [Grant number 20180229]. The funding body played no role in the design of the study and collection, analysis, and interpretation of data and in writing the manuscript.

\section{Availability of data and materials}

The datasets used and/or analyzed during the current study available from the corresponding author on reasonable request.

\section{Ethics approval and consent to participate}

The Institutional Review Boards of Jordan University of Science and Technology (IRB \#.20180229) and Consenting participants signed a written consent form.

\section{Consent for publication}

Not Applicable.

\section{Competing interests}

All authors declare that they have no conflict of interest.

\section{Author details}

${ }^{1}$ Adult health-nursing department, Faculty of Nursing, Jordan University of Science and Technology, P.O. Box: 3030, Irbid 22110, Jordan. ${ }^{2}$ Department of Physiotherapy, School of Rehabilitation Sciences, University of Jordan, Amman, Jordan.

Received: 6 July 2020 Accepted: 9 November 2020

Published online: 18 November 2020

\section{References}

1. Gupta, S. \& Gupta, A. (2019). Confusion in the older patient: a diagnostic approach. GM multi-platform resource. (c) pavilion publishing and media Itd 2020. Retrieved from: https://www.gmjournal.co.uk/confusion-in-the-olderpatient-a-diagnostic-approach. Accessed 6 July 2020

2. Qarni T, Salardini. A multifactor approach to mild cognitive impairment. Semin Neurol. 2019;39(2):179-87 @ 2019 Thieme Medical Publishers.

3. Langa KM, Levine DA. The diagnosis and management of mild cognitive impairment: a clinical review. JAMA. 2014;312(23):2551-61. https://doi.org/ 10.1001/jama.2014.13806.

4. Ferreira AR, Dias CC, Fernandes L. Needs in nursing homes and their relation with cognitive and functional decline, behavioral and psychological symptoms. Front Aging Neurosci. 2016;8:72. https://doi.org/10.3389/fnagi. 2016.00072.

5. Björk S, Juthberg C, Lindkvist M, Wimo A, Sandman PO, Winblad B, Edvardsson D. Exploring the prevalence and variance of cognitive impairment, pain, neuropsychiatric symptoms and ADL dependency among 
persons living in nursing homes; a cross-sectional study. BMC Geriatr. 2016; 16(1):154. https://doi.org/10.1186/s12877-016-0328-9.

6. Martin MD, Hancock GA, Richardson B, Simmons P, Katona C, Mullan E, et al. An evaluation of needs in elderly continuing-care settings. Int Psychogeriatr. 2002;14:379-88. https://doi.org/10.1017/s1041610202008578.

7. Ernsth Bravell M, Westerlind B, Midlöv P, Östgren C-J, Borgquist L, Lannering C, Mölstad S. How to assess frailty and the need for care? Report from the study of health and drugs in the elderly (SHADES) in community dwellings in Sweden. Arch Gerontol Geriatr. 2011;53:40-5. https://doi.org/10.1016/j. archger.2010.06.011.

8. Gustafsson M, Sandman PO, Karlsson S, Isaksson U, Schneede J, Sjölander M, Lövheim $\mathrm{H}$. Reduction in the use of potentially inappropriate drugs among old people living in geriatric care units between 2007 and 2013. Eur J Clin Pharmacol. 2015;71:507-15. https://doi.org/10.1007/s00228-015-1825-z.

9. Kijowska V, Szczerbińska K. Prevalence of cognitive impairment among long-term care residents: a comparison between nursing homes and residential homes in Poland. Eur Geriatr Med. 2018;9:467-76. https://doi.org/ 10.1007/s41999-018-0062-2.

10. Hayajneh $A A$, Ivanov LL, Rababa M. Jordanian nursing homes: admission policy analysis. Global J Health Sci. 2019;11(6):118-22.

11. Zheng L, Li G, Gao D, Wang S, Meng X, Wang C, Yuan H, Chen L. Cognitive frailty as a predictor of dementia among older adults: A systematic review and meta-analysis. Arch Gerontol Geriatrics. 2020;87. N.PAG. https://doi.org/ 10.1016/j.archger.2019.103997.

12. Zuckerman H, Pan Z, Park C, Brietzke E, Musial N, Shariq AS, lacobucci M, Yim SJ, Lui L, Rong C, McIntyre RS. Recognition and treatment of cognitive dysfunction in major depressive disorder. Front Psychiatry. 2018;9:655. https://doi.org/10.3389/fpsyt.2018.00655.

13. Christiansen L, Sanmartin Berglund J, Lindberg C, Anderberg P, Skär L. Health-related quality of life and related factors among a sample of older people with cognitive impairment. Nursing open. 2019;6(3):849-59. https:// doi.org/10.1002/nop2.265.

14. Park E, Park S, Kim J. Psychometric properties of the geriatric quality of lifedementia in older adults with dementia or mild cognitive impairment living in nursing homes. BMC Geriatr. 2019;19:281. https://doi.org/10.1186/s12877019-1307-8.

15. Villeneuve R, Meillon C, Bergua V, et al. Influence of pre-admission factors on quality of life and adaptation in nursing home residents with dementia: the QOL-EHPAD study protocol. BMC Geriatr. 2020;20:92. https://doi.org/10. 1186/s12877-020-1434-2.

16. Elashoff JD. nQuery Advisor .... Version 7.0 User's Guide. Los Angeles, CA. 2007. Retrieved from: https://cdn2.hubspot.net/hubfs/488764/nQ70_ Manual.pdf.

17. The Montreal Cognitive Assessment (MoCA). What are the severity levels for the MoCA?. Copyright 2019 Ziad Nasreddine MD. All rights reserved. Available from: https://www.mocatest.org/faq/. Accessed 6 July 2020.

18. Nasreddine ZS, Phillips NA, Bedirian V, Charbonneau S, Whitehead V, Collin I, et al. Montreal Cognitive Assessment, MoCA: A brief screening tool for mild cognitive impairment. J Am Geriatr Soc. 2005;53(4):695-9.

19. Greenberg S. Try this: the Geriatric Depression Scale (GDS): The Hartford Institute for Geriatric Nursing, New York University, College of Nursing; 2012. p. 4. Retireved from: https://wwwoundcare.ca/Uploads/ContentDocuments/ Geriatric\%20Depression\%20Scale.pdf. Accessed 6 July 2020.

20. Sabbah I, Drouby N, Sabbah S, Retel-Rude N, Mercier M. Quality of life in rural and urban populations in Lebanon using SF-36 health survey. Health Qual Life Outcomes. 2003;1:30-14. https://doi.org/10.1186/1477-7525-1-30.

21. Gobbens R, van Assen M, Luijkx K, Wijnen-Sponselee M, Schols J. The Tilburg frailty Indicator: psychometric properties. J Am Med Dir Assoc. 2010; 11(5):344-55. https://doi.org/10.1016/j.jamda.2009.11.003.

22. Hayajneh AA. The psychometric properties of the Arabic Version of the Tilburg frailty Indicator. Global J Health Sci. 2019;11(9):123-33. https://doi. org/10.5539/gjhs.v11n9p123.

23. Al-btoush A. Relation between the psychological impact of Presbycusis and hearing handicap inventory for the elderly using screening Version in Jordan. Middle East J Age Ageing. 2012;9(5):23-5.

24. Bani-Issa W, Almomani F, Eldeirawi K. Urinary incontinence among adult women with diabetes in Jordan: epidemiology, correlates and perceived impact on emotional and social well-being. J Clin Nurs. 2014;23(17-18):2451-60.

25. Abdelmoneium AO, Alharahsheh ST. Family home caregivers for old persons in the Arab region: perceived challenges and policy implications. Open J Soc Sci. 2016:4:151-64. https://doi.org/10.4236/jss.2016.41019.
26. Hussein S, Ismail M. Ageing and elderly Care in the Arab Region: policy challenges and opportunities. Ageing Int. 2017;42(3):274-89. https://doi.org/ 10.1007/s12126-016-9244-8.

27. Arafa, Mohamed A., What's new in the residential Care of the Elderly in the Arab and Islamic world? The case of Egypt. Towards human rights in residential Care for Older Persons: international perspectives. 2015: (chapter 2, Routledge, London \& New York), Available at SSRN: https://ssrn.com/ abstract=2710357. Accessed 6 July 2020.

28. Li W, Sun L, Li G, Xiao S. Prevalence, influence factors and cognitive characteristics of mild cognitive impairment in type 2 diabetes mellitus. Front Aging Neurosci. 2019;11:180. https://doi.org/10.3389/fnagi.2019.00180.

29. Makizako H, Shimada H, Doi T, et al. Comorbid mild cognitive impairment and depressive symptoms predict future dementia in community older adults: a 24-month follow-up longitudinal study. J Alzheimers Dis. 2016; 54(4):1473-82 http://search.ebscohost.com/login.aspx?direct=true\&db= cmedm\&AN=27589518\&site=ehost-live. Accessed April 15, 2020.

30. Ma L. Depression, anxiety, and apathy in mild cognitive impairment: current perspectives. Front Aging Neurosci. 2020;12:9. https://doi.org/10.3389/fnagi. 2020.00009.

31. Devanand DP, Pelton GH, D'Antonio K, et al. Donepezil treatment in patients with depression and cognitive impairment on stable antidepressant treatment: a randomized controlled trial. Am J Geriatr Psychiatr. 2018;26(10):1050-60. https://doi.org/10.1016/j.jagp.2018.05.008.

32. Atif $M$, Saleem $Q$, Scahill S. Depression and mild cognitive impairment (MCl) among elderly patients with type 2 diabetes mellitus in Pakistan: possible determinants. Int J Diabetes Dev Ctries. 2018;38:312-20. https://doi.org/10. 1007/s13410-017-0600-3.

33. Liu HY, Tsai WC, Chiu MJ, Tang LY, Lee HJ, Shyu YL. Mild cognitive impairment in combination with comorbid diabetes mellitus and hypertension is negatively associated with health-related quality of life among older persons in Taiwan. Qual Life Res. 2019;28(5):1281-91. https:// doi.org/10.1007/s11136-019-02101-3.

34. Chen T-B, Yiao S-Y, Sun Y, Lee H-J, Yang S-C, Chiu M-J, et al. Comorbidity and dementia: a nationwide survey in Taiwan. PLoS One. 2017;12(4): e0175475. https://doi.org/10.1371/journal.pone.0175475.

35. Solomon A, Dobranici L, Kåreholt I, Tudose C, Lăzărescu M. Comorbidity and the rate of cognitive decline in patients with Alzheimer dementia. Int J Geriatric Psychiatry. 2011;26(12):1244-51. https://doi.org/10.1002/gps.2670.

36. Stephan BC, Brayne C, Savva GM, Matthews FE. Medical Research Council cognitive function and ageing study. Occurrence of medical co-morbidity in mild cognitive impairment: implications for generalization of $\mathrm{MCl}$ research. Age Ageing. 2011;40(4):501-7. https://doi.org/10.1093/ageing/afr057.

37. Jacob L, Haro JM, Koyanagi A. Relationship between living alone and common mental disorders in the 1993, 2000 and 2007 National Psychiatric Morbidity Surveys. PLoS One. 2019;14(5):e0215182. https://doi.org/10.1371/ journal.pone.0215182.

38. Elliott I. Poverty and Mental Health: A review to inform the Joseph Rowntree Foundation's Anti-Poverty Strategy. London: Mental Health Foundation; 2016

39. Mathews SB, Arnold SE, Epperson CN. Hospitalization and cognitive decline: can the nature of the relationship be deciphered? Am J Geriatr Psychiatr. 2014;22(5):465-80. https://doi.org/10.1016/j.jagp.2012.08.012.

40. Qin T, Yan M, Fu Z, et al. Association between anemia and cognitive decline among Chinese middle-aged and elderly: evidence from the China health and retirement longitudinal study. BMC Geriatr. 2019;19:305. https://doi.org/ 10.1186/s12877-019-1308-7.

41. Li M, Huang Y, Liu Z, Shen R, Chen H, Ma C, Zhang T, Li S, Prince M. The association between frailty and incidence of dementia in Beijing: findings from 10/66 dementia research group population-based cohort study. BMC Geriatr. 2020;20(1):1-9. https://doi.org/10.1186/s12877-020-01539-2.

42. Mosti CB, Rog LA, Fink JW. Differentiating mild cognitive impairment and cognitive changes of Normal aging. In: Ravdin L, Katzen H, editors. Handbook on the Neuropsychology of Aging and Dementia. Clinical handbooks in neuropsychology. Cham.: Springer; 2019.

43. DeCarli C. MCl: prevalence, prognosis, an etiology and treatment. Lancet Neurol. 2003;2:15-21.

44. Karrer M, Hirt J, Zeller A, et al. What hinders and facilitates the implementation of nurse-led interventions in dementia care? A scoping review. BMC Geriatr. 2020;20:127. https://doi.org/10.1186/s12877-020-01520-z.

45. Goossens B, Sevenants A, Declercq A, et al. 'We DECide optimized' - training nursing home staff in shared decision-making skills for advance care 
planning conversations in dementia care: protocol of a pretest-posttest cluster randomized trial. BMC Geriatr. 2019;19:33. https://doi.org/10.1186/ s12877-019-1044-z.

46. Zahirovic I, Torisson G, Wattmo C, et al. Psychotropic and anti-dementia treatment in elderly persons with clinical signs of dementia with Lewy bodies: a cross-sectional study in 40 nursing homes in Sweden. BMC Geriatr. 2018;18:50. https://doi.org/10.1186/s12877-018-0740-4.

\section{Publisher's Note}

Springer Nature remains neutral with regard to jurisdictional claims in published maps and institutional affiliations.

Ready to submit your research? Choose BMC and benefit from:

- fast, convenient online submission

- thorough peer review by experienced researchers in your field

- rapid publication on acceptance

- support for research data, including large and complex data types

- gold Open Access which fosters wider collaboration and increased citations

- maximum visibility for your research: over $100 \mathrm{M}$ website views per year

At $B M C$, research is always in progress.

Learn more biomedcentral.com/submissions 